\title{
Experimental measurements about harmonic current mitigation of electric vehicle battery chargers
}

\author{
L. Sainz ${ }^{1}$ and J. Balcells ${ }^{2}$ \\ ${ }^{1}$ Department of Electrical Engineering \\ E.T.S.E.I.B, Technical University of Catalonia (UPC) \\ Av. Diagonal 647, 08028 Barcelona (Spain) \\ Phone/Fax number:+0034 93 4011759/+0034 93 4017433, e-mail: sainz@ee.upc.edu \\ ${ }^{2}$ Department of Electronics Engineering \\ E.T.S.E.I.T, Technical University of Catalonia (UPC) \\ Colom 1, 08222 Terrassa (Spain) \\ Phone/Fax number:+0034 93 7398193/+0034 93 7398016, e-mail: josep.balcells@upc.edu
}

\begin{abstract}
The expected high penetration of battery chargers for electric vehicles (EV) in electric networks is foreseen as a potential problem for power quality. Battery chargers are nonlinear devices that inject harmonic currents and pollute network voltages. Thus, their harmonic emissions must be analyzed and reduced by harmonic mitigation techniques to avoid future problems. This paper analyzes and reports some real case measurements of harmonics injected by single- and three-phase battery chargers and their attenuation using line choke inductances.
\end{abstract}

\section{Key words}

Battery chargers, harmonics, power quality.

\section{Introduction}

The growing presence of non-linear loads (NLLs) in commercial, industrial and residential installations has led to a rise in harmonic levels in power distribution systems. NLLs in such installations are generally smallpower single-phase loads in the range of $300-3 \mathrm{~kW}$ and high-power three-phase loads in the range of $15-75 \mathrm{~kW}$. Small-power NLLs typically comprise switched-mode power supplies for office and entertainment equipment. The most relevant high-power NLLs consist of threephase diode rectifiers used in adjustable-speed drives (ASDs), HVAC equipment and phase-controlled rectifiers for temperature regulation of residential households. In the future, a large increase of single and three-phase battery chargers is expected in electric installations, as EVs are becoming an ecologically attractive alternative to internal combustion (IC) cars. In particular, chargers will become widespread in residential networks. For this reason, several studies in the literature attempt to predict the harmonic impact of these nonlinear loads on the network. Some investigate the harmonic emissions of battery chargers and clusters of these loads in the network [1]-[5]. Others focus on the effects of these devices on the supply system [6]-[9]. Thus, due to the increasing importance of the battery charger power quality problem, different techniques, such as improvements in chargers [10], [11] or active filters [12], have been proposed to mitigate the harmonic currents injected by these loads. Among of them, line choke inductances appear as the simplest yet effective method.

The paper analyzes the use of choke inductances to reduce the harmonic emission of single- and three-phase battery chargers. The study is supported by experimental measurements in actual installations.

\section{EV Battery Chargers}

\section{A. Single-phase Battery Chargers}

Fig. 1(a) illustrates the typical equivalent circuit of single-phase battery chargers. It consists of a singlephase diode bridge with an AC inductor $L$ (together with its associated resistance $R$ ), the resistance $R_{C}$ and the inductance $L_{C}$ of the charger circuit and the emf $E$ of the battery under charge (together with its internal resistance $R_{E}$ ). The inductance $L_{C}$ is commonly lower than the inductance $L$. As an example of charger behavior, Fig. 1(b) shows the AC current $i$ drawn by the singlephase bridge considering that $L_{C}<<L$. The supply voltage $v$ and the battery voltage $E$ are also plotted as

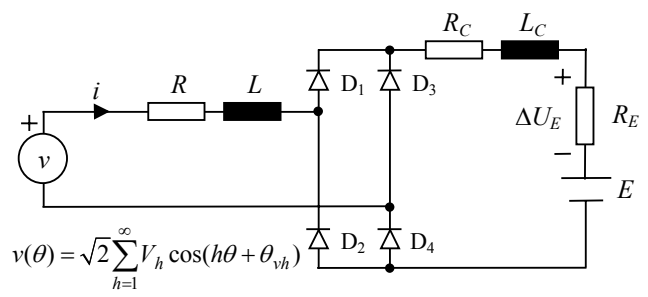

(a)

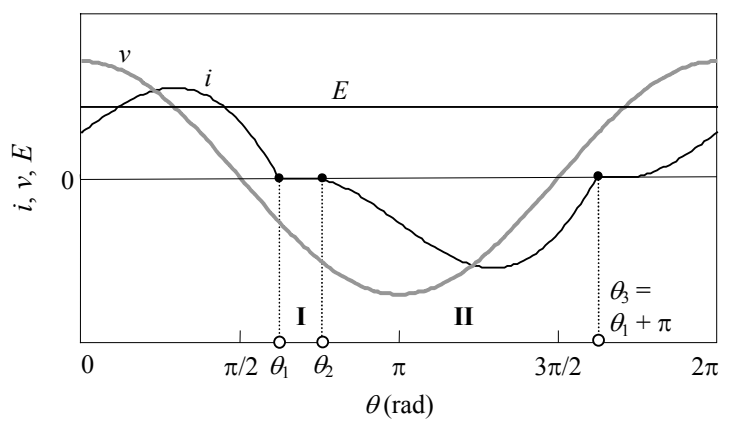

(b)

Fig. 1. Analysis of single-phase battery chargers: a) Equivalent circuit. b) Voltage and current waveforms. 

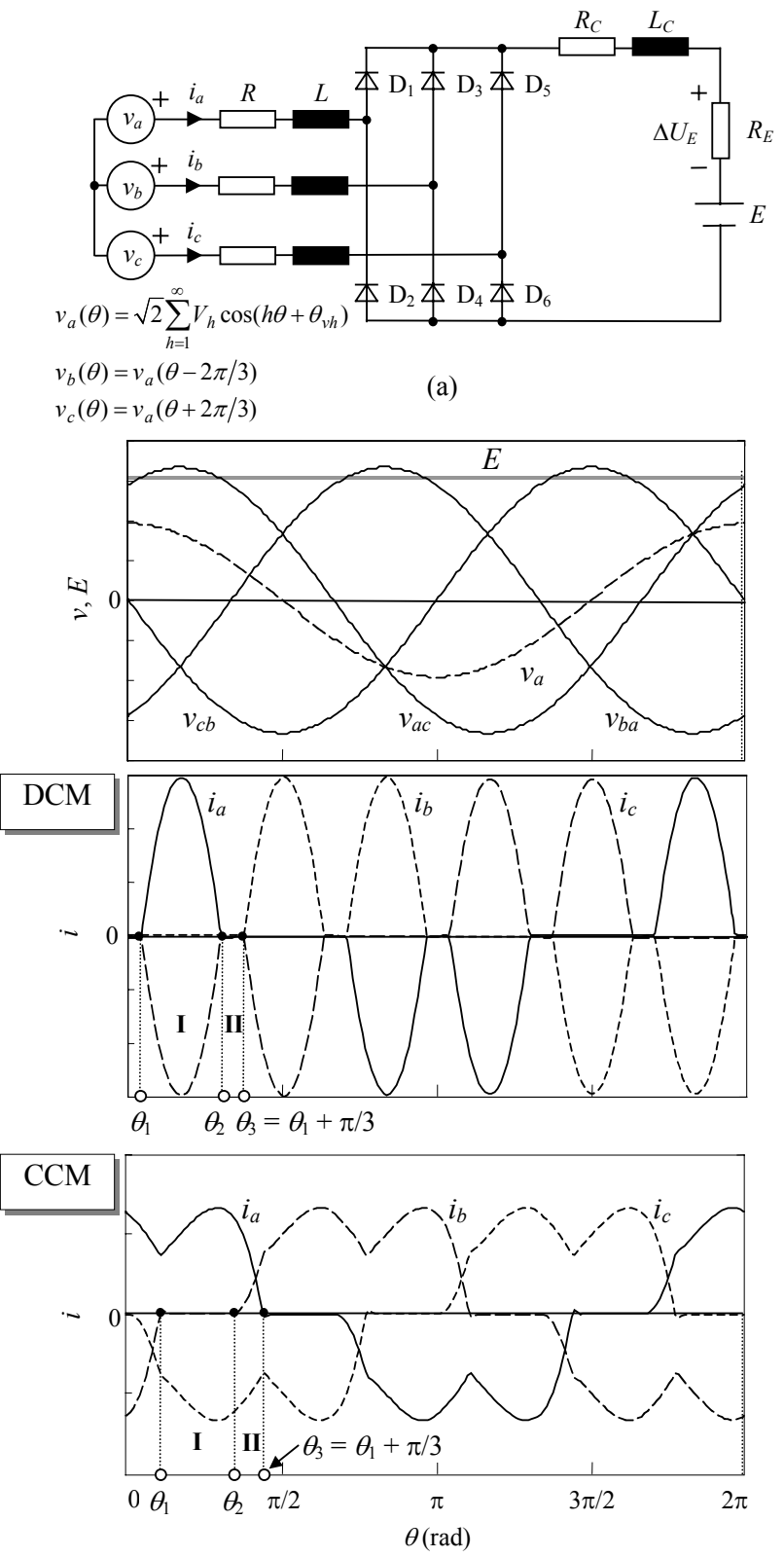

(b)

Fig. 2. Analysis of three-phase battery chargers: a) Equivalent circuit. b) Voltage and current waveforms in DCM. c) Voltage and current waveforms in CCM.

reference. This circuit operates in discontinuous conduction mode where two different states can be distinguished:

- The diodes are off and the current $i$ is zero [e.g., segment I in Fig. 1(b)].

- The current $i$ flows through the rectifier diodes and charges the battery [e.g., segment II in Fig. 1(b)].

The commutation angles $\theta_{1}$ and $\theta_{2}$, which define the charger AC current considering half-wave symmetry conditions, are illustrated in Fig. 1(b). To obtain the instantaneous waveshape of the current, these angles must be determined by analyzing the circuit states corresponding to the current segments I and II. The analysis of the circuit in Fig. 1(a) reveals that the equations describing the circuit behavior in segment I $\left(\theta_{1}<\theta<\theta_{2}\right)$ and segment II $\left(\theta_{2}<\theta<\theta_{3}=\theta_{1}+\pi\right)$ are

$$
\text { (I): } i^{(\mathrm{I})}=0, \quad(\mathrm{II}): X_{T} \frac{d i^{(\mathrm{II})}}{d \theta}+R_{T} \cdot i^{(\mathrm{II})}-E=v,
$$

where $R_{T}=R+R_{C}+R_{E}, X_{T}=\left(L+L_{C}\right) \cdot \omega, \omega=2 \pi f$ and $f$ is the fundamental frequency. The commutation angles and the expression of the AC current waveform are obtained by solving (1) and considering the symmetry and boundary conditions.

Thus, considering sinusoidal supply voltage $\left[V_{h}=0\right.$ with $h \neq 1$ in Fig. 1(a)] and neglecting the DC side inductance $L_{C}$ and the circuit resistances $R, R_{C}$ and $R_{E}$, the equations for approximately calculating the commutation angles are obtained from (1) [13]:

$$
\begin{aligned}
& \sqrt{2} V_{1} \cos \left(\theta_{2}-\pi\right)=E, \\
& \sqrt{2} V_{1}\left(\sin \left(\theta_{1}\right)+\sin \left(\theta_{2}\right)\right)=E\left(\pi-\theta_{2}+\theta_{1}\right),
\end{aligned}
$$

where $V_{1}$ is the rms value of the fundamental supply voltage $v$ in Fig. 1(a).

\section{B. Three-phase Battery Chargers}

Fig. 2(a) illustrates the typical equivalent circuit of threephase battery chargers. It consists of a three-phase diode bridge with three AC inductors $L$ (together with their associated resistance $R$ ), the resistance $R_{C}$ and the inductance $L_{C}$ of the charger circuit and the emf $E$ of the battery under charge (together with its internal resistance $R_{E}$ ). The inductance $L_{C}$ is commonly lower than the inductances $L$. As an example of charger behavior in discontinuous and continuous conduction modes (DCM and CCM, respectively), Fig. 2(b) shows the AC currents $i_{a}, i_{b}$ and $i_{c}$ drawn by the three-phase configuration considering that $L_{C}<<L$. The supply voltages $v_{a}, v_{a c}, v_{b a}$ and $v_{c b}$ and the battery voltage $E$ are also plotted as a reference.

When the circuit operates in DCM, the following two states can be distinguished:

- The currents flow through the rectifier diodes and charge the battery [e.g., segment I in Fig. 2(b)].

- The diodes are off and the currents are zero [e.g., segment II in Fig. 2(b)].

When the circuit operates in CCM, the following two states can be distinguished:

- The current flows through one of the odd diodes, charging the battery, and returns through one of the even diodes [e.g., segment I in Fig. 2(b)].

- The current flows through one/two of the odd diodes, charging the battery, and returns through two/one of the even diodes [e.g., segment II in Fig. 2(b)].

The commutation angles $\theta_{1}$ and $\theta_{2}$, which define the charger current in DCM and CCM considering half-wave symmetry conditions, are illustrated in Fig. 2(b). To obtain the currents drawn by the circuit, these angles must be determined by analyzing the circuit topologies corresponding to states I and II (current segments I and II). Thus, the analysis of the circuit in Fig. 2(a) reveals that the equations describing the circuit behavior, i.e. the AC current waveforms of segment I $\left(\theta_{1}<\theta<\theta_{2}\right)$ and segment II $\left(\theta_{2}<\theta<\theta_{3}=\theta_{1}+\pi / 3\right)$ in DCM are (3) 


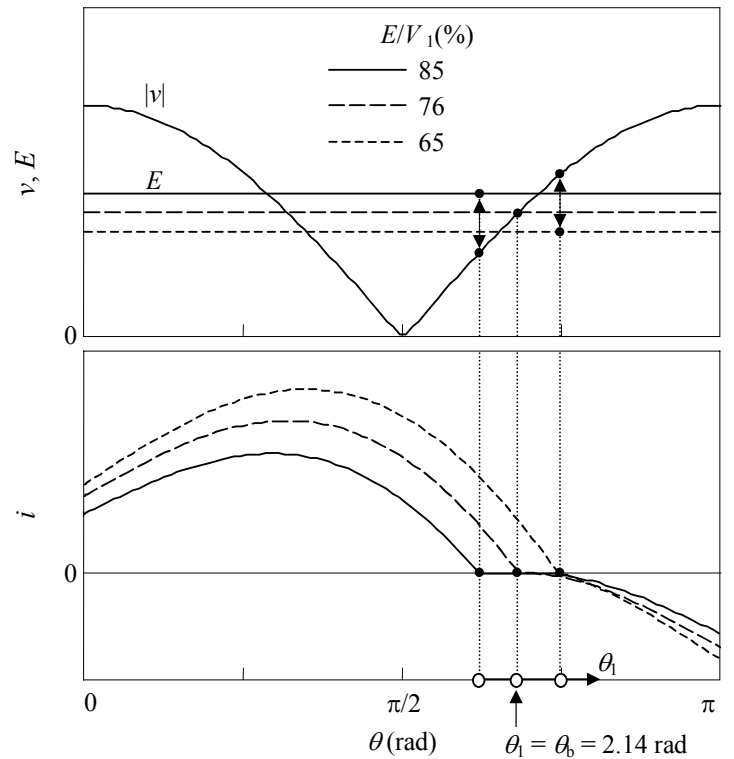

Fig. 3. Transition from discontinuous conduction mode to continuous conduction mode in single-phase battery chargers with null $L_{C}, R_{C}$ and $R_{E}$ values.

$$
\text { (I): } X_{T 1} \frac{d i_{a}^{(\mathrm{I})}}{d \theta}+R_{T 1} \cdot i_{a}^{(\mathrm{I})}+E=v_{a c}, \quad(\mathrm{II}): i_{a}^{(\mathrm{II})}=0,
$$

and the equations in CCM are (4)

(I): $X_{T 1} \frac{d i_{a}^{(\mathrm{I})}}{d \theta}+R_{T 1} \cdot i_{a}^{(\mathrm{I})}+E=v_{a c}$,

(II):

$$
\begin{aligned}
& X_{T 1} \frac{d i_{a}^{(\mathrm{II})}}{d \theta}+R_{T 1} \cdot i_{a}^{(\mathrm{II})}+X_{T 2} \frac{d i_{b}^{(\mathrm{II})}}{d \theta}+R_{T 2} \cdot i_{b}^{(\mathrm{II})}+E=v_{a c}, \\
& X_{T 1} \frac{d i_{b}^{(\mathrm{II})}}{d \theta}+R_{T 1} \cdot i_{b}^{(\mathrm{II})}+X_{T 2} \frac{d i_{a}^{(\mathrm{II})}}{d \theta}+R_{T 2} \cdot i_{a}^{(\mathrm{II})}+E=v_{b c},
\end{aligned}
$$

where $\quad R_{T 1}=2 R+R_{C}+R_{E}, \quad R_{T 2}=R+R_{C}+R_{E}$, $X_{T 1}=\left(2 L+L_{C}\right) \cdot \omega \quad$ and $\quad X_{T 2}=\left(L+L_{C}\right) \cdot \omega$. The commutation angles and the expression of the AC current waveform are obtained by solving (3) or (4) under the symmetry and boundary conditions.

Thus, considering sinusoidal supply voltage $\left[V_{h}=0\right.$ with $h \neq 1$ in Fig. 2(a)] and neglecting the DC inductance $L_{C}$ and the circuit resistances $R, R_{C}$ and $R_{E}$, the equations for approximately calculating the commutation angles in CCM are obtained from (4) [13]:

$$
\begin{aligned}
& \sqrt{2} V_{1} \cos \left(\theta_{2}-\pi\right)=\frac{2 \pi}{3} E \\
& \sqrt{2} V_{1}\left(\sin \left(\theta_{1}\right)+\sin \left(\theta_{2}\right)\right)=\frac{2 \pi}{3} E\left(\frac{4 \pi}{3}-\theta_{2}+\theta_{1}\right),
\end{aligned}
$$

where $V_{1}$ is the rms value of the line-to-neutral supply voltages in Fig. 2(a).

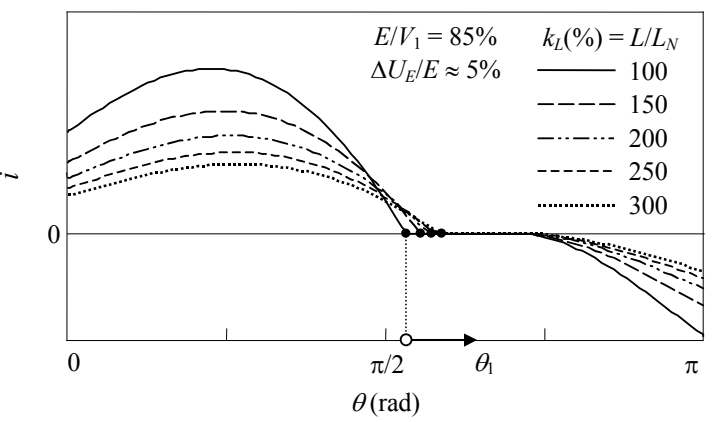

Fig. 4. Influence of $L$ on the transition from discontinuous conduction mode to continuous conduction mode in singlephase battery chargers with null $L_{C}$ and $R_{C}$ values.

\section{Mitigation of Battery Charger Harmonics by Line Choke Inductances}

The mitigation method is based on the increase in AC side inductance, $L$, by a choke insertion. This leads to a growth in current pulse width and thus to a decrease in the harmonic contents of the current wave (small values of the $\mathrm{AC}$ inductance value, $L$, result in a sharp current pulse and high harmonic contents).

\section{A. Single-phase Battery Chargers}

From (2), we can derive that the commutation angles (i.e. the current pulse width) approximately depend on the ratio $E / V$ only. In the boundary between the discontinuous and continuous conduction modes, the commutation angles coincide $\left(\theta_{1}=\theta_{2}=\theta_{\mathrm{b}}\right)$, and the boundary conditions are obtained from (2) [13]:

$$
\left.\begin{array}{c}
\sqrt{2} V_{1} \cos \left(\theta_{\mathrm{b}}-\pi\right)=E_{\mathrm{b}} \\
\sqrt{2} V_{1} \sin \left(\theta_{\mathrm{b}}\right)=E_{\mathrm{b}} \pi / 2
\end{array}\right\} \Rightarrow \begin{gathered}
\theta_{\mathrm{b}}=2.14 \mathrm{rad} \\
E_{\mathrm{b}} / V_{1}=75.9 \%
\end{gathered}
$$

Fig. 3 shows the influence of the ratio $E / V_{1}$. It may be observed that, for commutation angles $\theta_{1}$ smaller than $\theta_{\mathrm{b}}$, the current extinguishes when the emf $E$ is greater than the instantaneous supply voltage and the current through the diodes stops at this point (discontinuous conduction). On the other hand, for commutation angles $\theta_{1}$ greater than $\theta_{b}$, the emf $E$ is always smaller than the supply voltage, and the current continues flowing through the diodes all the time (continuous conduction).

According to (2), the AC inductance has no influence on the commutation angles. Actually this is not true due to the battery internal resistance $R_{E}$, as illustrated in Fig. 4 considering a resistance $R_{E}$ causing a voltage drop $\Delta U_{E}$ (Fig. 1) of about $5 \%$ of $E$. However, it is worth noting that this influence is too small for choke inductances to be considered a good method to mitigate the harmonic emissions of single-phase battery chargers. This is also true with non-sinusoidal supply voltage. The analysis results of Fig. 3 and Fig. 4 were obtained by PSpice simulations.

\section{B. Three-phase Battery Chargers}




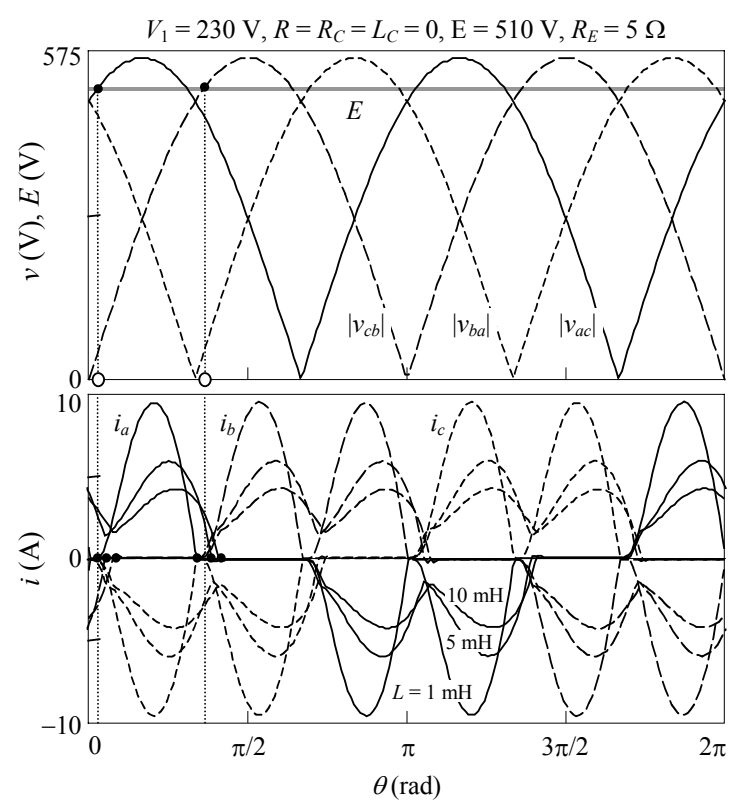

(a)

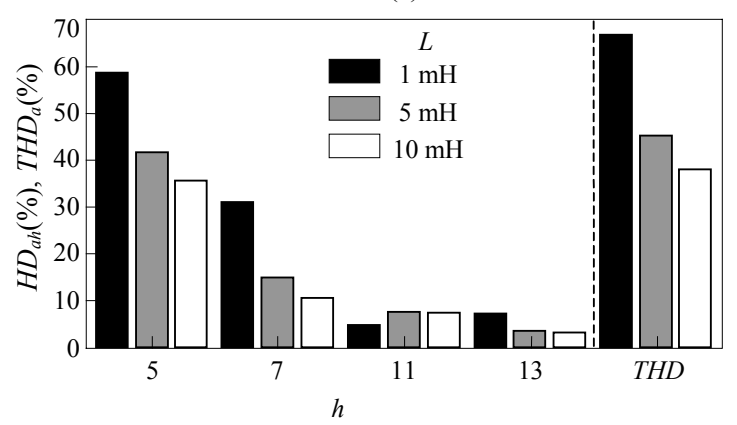

(b)

Fig. 5. Influence of $L$ on the transition from discontinuous conduction mode to continuous conduction mode in threephase battery chargers: a) Voltage and current waveforms. b) Current harmonic distortion of phase $a$.

From (5), we can see that the commutation angles approximately depend on the ratio $E / V_{1}$ only. In the boundary between the discontinuous and the continuous conduction modes of the battery charger, the commutation angles in $\mathrm{CCM}$ verify that $\theta_{2}=\theta_{3}=\theta_{1}+\pi / 3$. Thus, the boundary conditions can be obtained from (5) by imposing the previous relationship between commutation angles.

As with single-phase chargers, the AC inductance seem to have no influence on the commutation angles (5), but actually this is not true due to the internal battery

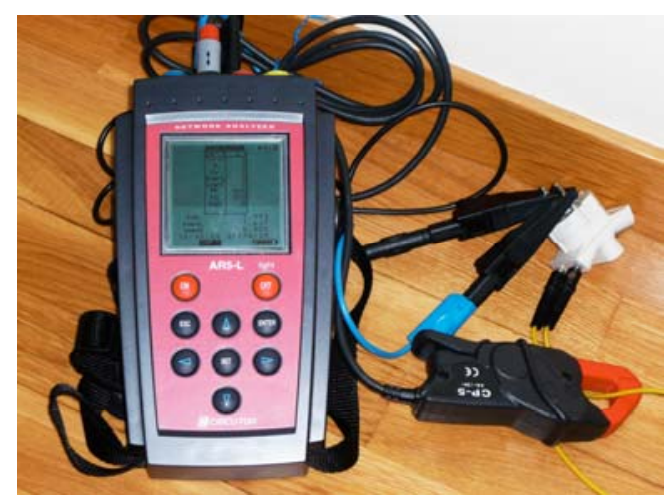

Fig. 6. Power network analyzer AR5-L of CIRCUTOR. resistance $R_{E}$. This is illustrated in Fig. 5 considering a resistance $R_{E}=5 \Omega$ causing a voltage drop $\Delta U_{E}$ (Fig. 2) of about $5 \%$ of $E$. It can be observed that the AC inductance influence on the three-phase battery charger is much larger than on the single-phase battery charger. Thus, the addition of choke inductances mitigates the harmonic emissions of this kind of battery chargers. This is also true with non-sinusoidal supply voltage. The analysis was performed by PSpice simulations.

\section{Experimental measurements}

To validate the previous study, measurements carried out at an actual installation with the power network analyzer AR5-L of CIRCUTOR (Fig. 6) are presented.

The installation was a garage where several garbage trucks were parked during midday rest and overnight. The total supply points were distributed between three lines having 20 points for single-phase chargers and 5 points for three-phase chargers. The single-phase chargers supplied power to the batteries of Piaggio Porter vehicles were connected to line-to-neutral supply lines. The three-phase chargers supplied supplied power to the batteries of FIAT Ducato vehicles were connected to line-to-line supply lines. To study the harmonic emission mitigation, individual measurements of the two types of vehicle chargers to be connected in the supply installation $(2.2 \mathrm{~kW}$ single-phase charger of the Piaggio Porter vehicles and $6.6 \mathrm{~kW}$ three-phase charger of the FIAT Ducato vehicles) were made. The battery chargers were tested in two conditions: a) Directly connected to the supply lines and b) Inserting an $\mathrm{AC}$ choke inductance with a rated voltage drop of $4 \%$ at $50 \mathrm{~Hz}$ (inductances of $3 \mathrm{mH}$ for both cases) between the supply line and the charger.

The AR5-L power analyzer can record several data (e.g., active and reactive powers, power factor, voltage and current waveforms...) for long time periods with a programmable time interval between readings. This allowed measuring the currents drawn by the battery charger before and after the insertion of the choke inductances, as well as analyzing their influence on those currents. All the recorded voltage and current waveforms were stored on a hard disk and treated with customized MATLAB software for harmonic analysis. Thus, assuming that the magnitude of the waveforms is stationary, the Fourier transform was applied to a 20-ms rectangular window providing a $50-\mathrm{Hz}$ frequency resolution. The harmonic distortion $H D_{h}$ and the total harmonic distortion THD defined as follows

$$
\begin{aligned}
& H D_{h}(\%)=100 \frac{I_{h}}{I_{1}} \quad(h \neq 1), \\
& T H D(\%)=100 \frac{\sqrt{\sum_{h=3}^{\infty} I_{h}^{2}}}{I} \quad\left(I=\sqrt{\sum_{h=1}^{\infty} I_{h}^{2}}\right),
\end{aligned}
$$




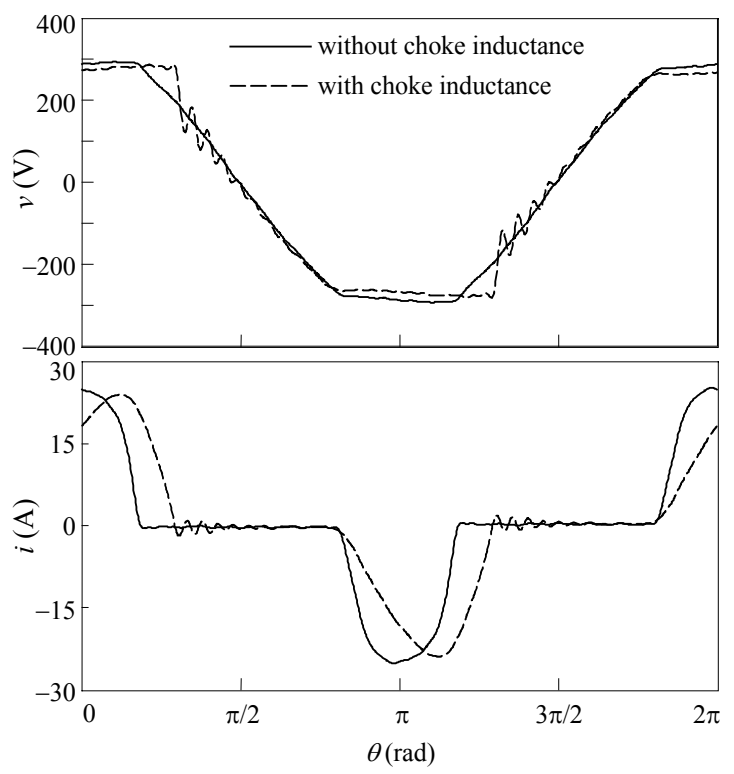

(a)

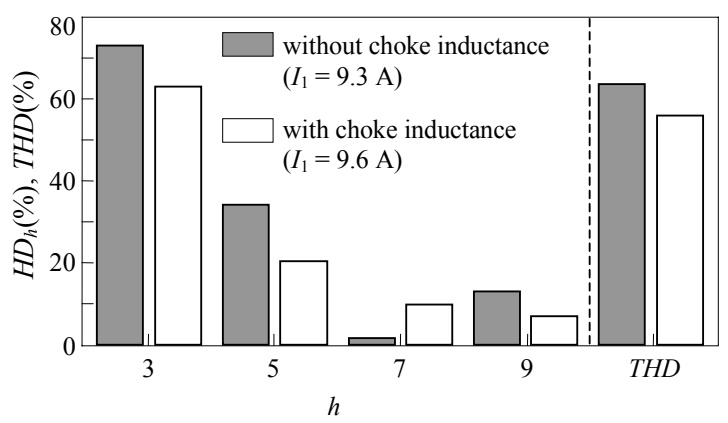

(b)

Fig. 7. Measurements of the choke inductance influence on the single-phase battery charger behavior: a) Voltage and current waveforms. b) Current harmonic distortion.

The measurements on single-phase chargers are shown in Fig. 7. As mentioned in Section 3.A, the influence of the choke inductances on the AC current is small. Thus, the harmonic current reduction that occurs with the inductance connection is not enough to consider this connection an effective measure to mitigate battery charger harmonic emissions.

\section{B. Three-phase Battery Chargers Measurements}

The measurements on three-phase chargers are shown in Fig. 8. As mentioned in Section 3.B, the influence of the choke inductances on the AC current allows changing the battery charger behavior from DCM to CCM, thus reducing its harmonic emissions.

\section{Conclusion}

The paper studies the use of AC choke inductances to reduce the harmonic emissions of single- and three-phase battery chargers. The technique is useful in the threephase case but useless in the single-phase case because the influence of the choke inductances on $\mathrm{AC}$ current pulse width is small. The study and final conclusions are supported by experimental measurements in a garage installation.

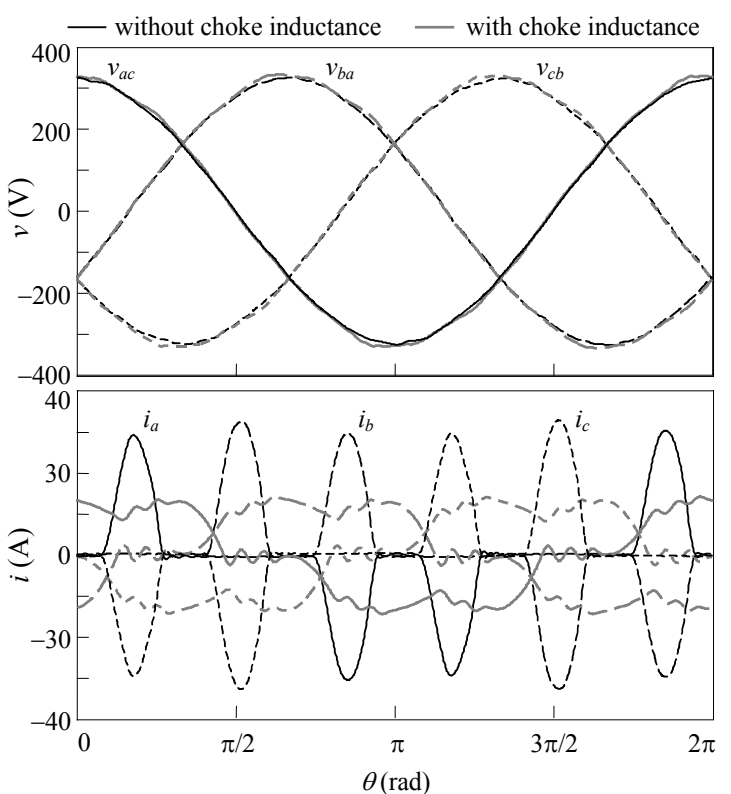

(a)

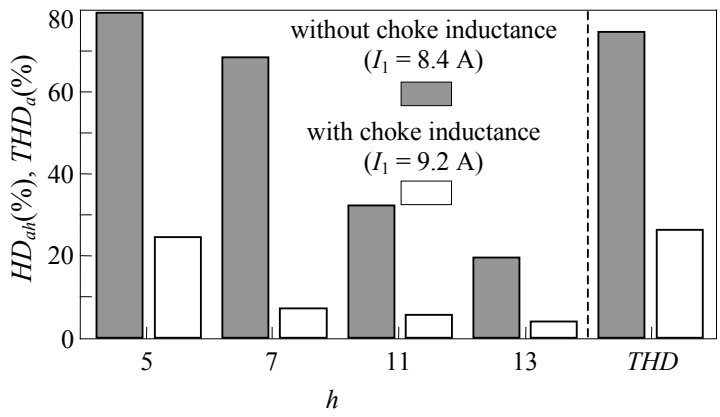

(b)

Fig. 8. Measurements of the choke inductance influence on the three-phase battery charger behavior: a) Voltage and current waveforms. b) Current harmonic distortion of phase $a$.

\section{Acknowledgement}

The authors would like to thank the PFC Division Technical Department of CIRCUTOR S.A. for its contribution to this paper with the battery charger measurements.

This research is carried out with the financial support of grant DPI2010-15448, which the authors gratefully acknowledge.

\section{References}

[1] J. A. Orr, A. E. Emanuel and K. W. Oberg, "Current harmonics generated by a cluster of electric vehicle chargers", IEEE Trans. on Power Apparatus and Systems, Vol. PAS-101, No. 3, March 1982, pp. 691-700.

[2] J. A. Orr, A. E. Emanuel and D. J. Pileggi, "Current harmonics, voltage distortion, and powers associated with battery chargers. Part I: Comparisons among different types of chargers", IEEE Trans. on Power Apparatus and Systems, Vol. PAS-101, No. 8, August 1982, pp. 27032710.

[3] J. A. Orr, A. E. Emanuel and D. J. Pileggi, "Current harmonics, voltage distortion and powers associated with electric vehicle battery chargers distributed on the residential power systems", IEEE Trans. on Industry 
Applications, Vol. IA-20, No. 4, July/August 1984, pp. 727-734.

[4] P. T. Staats, W. M. Grady, A. Arapostathis and R. S. Thallam, "A statistical method for predicting the net harmonic currents generated by a concentration of electric vehicle battery chargers", IEEE Trans. on Power Delivery, Vol. 12, No. 3, July 1997, pp. 1258-1266.

[5] P. T. Staats, W. M. Grady, A. Arapostathis and R. S. Thallam, "A statistical analysis of the effect of electric vehicle battery charging on distribution system harmonic voltages", IEEE Trans. on Power Delivery, Vol. 13, No. 2, April 1998, pp. 640-646.

[6] P. T. Staats, W. M. Grady, A. Arapostathis and R. S. Thallam, "A procedure for derating a substation transformer in the presence of widespread electric vehicle battery charging", IEEE Trans. on Power Delivery, Vol. 12, No. 4, October 1997, pp. 1562-1568.

[7] Y. J. Wang, R. M. O'Connell and G. Brownfield, "Modeling and prediction of distribution system voltage distortion caused by nonlinear residential loads", IEEE Trans. on Power Delivery, Vol. 16, No. 4, October 2001, pp. 744-751.

[8] T. A. Buchh and A. Domijan Jr., "Harmonic effect of electric vehicle loads", Int. Journal of Power and Energy Systems, Vol. 21, No. 2, 2001, pp. 62-66.
[9] J. C. Gómez and M. M. Morcos, "Impact of EV battery chargers on the power quality of distribution systems", IEEE Trans. on Power Delivery, Vol. 18, No. 3, July 2003, pp. 975-981.

[10] P. Bartholomeus and P. Le Moigne, "Battery charger with high quality input waveforms", in Proc. of the IEEE International Symposium on Industrial Electronics 1995, pp. 574-579.

[11] K. A. Buckle and J. W. Luce, "Battery vehicle charger design eliminates harmonic current generation", in Proc. of the IEEE Southeascon '96, Bringing Together Education, Science and Technology 1996, pp. 561-564.

[12] J. Balcells and J. García-Fàbrega, "Impact of Plug-in Electric Vehicles on the Supply Grid", Proceedings of IEEE Vehicle Power and Propulsion Conference (VPPC2010), Lille 1-3 September 2010; Ref: 978-14244-8218-4/10/\$26.00 (C2010 IEEE

[13] J. G. Mayordomo, A. Hernández, R. Asensi, L. F. Beites and M. Izzeddine, "A unified theory of uncontrolled rectifiers, discharge lamps and arc furnaces. PART I: An analytical approach for normalised harmonic emission calculations", in Proc. $8^{\text {th }}$ IEEE ICHQP 1998, pp. 740748 . 